Review

\title{
Fibroblast growth factor receptor signaling as therapeutic targets in female reproductive system cancers
}

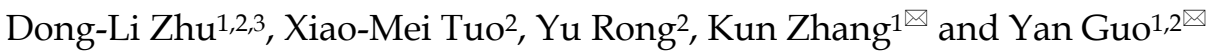 \\ 1. Key Laboratory of Biomedical Information Engineering of Ministry of Education, Department of Trauma Surgery, Honghui Hospital, College of Medicine, \\ Xi'an Jiaotong University, Xi'an, Shaanxi, P. R. China. \\ 2. Biomedical Informatics \& Genomics Center, School of Life Science and Technology, Xi'an Jiaotong University, Xi'an, Shaanxi, P. R. China, 710054. \\ 3. Research institute of Xi'an Jiaotong University, Hangzhou, Zhejiang, P. R. China, 311215. \\ $\square$ Corresponding author: E-mail: guoyan253@xjtu.edu.cn (Y.G), hhyyzk@126.com (K. Z).
}

(0) The author(s). This is an open access article distributed under the terms of the Creative Commons Attribution License (https://creativecommons.org/licenses/by/4.0/). See http://ivyspring.com/terms for full terms and conditions.

Received: 2020.02.09; Accepted: 2020.07.25; Published: 2020.10.21

\begin{abstract}
Ovarian cancer, cervical cancer and endometrial cancer are three relatively common malignant cancers of the female reproductive system. Despite improvements in female genital tract cancer detection and development of new therapeutic approaches, there are still poor prognoses and some do not respond to therapeutic patterns, displaying low survival and high frequency of recurrence. In an era of personalized medicine, novel therapeutic approaches with greater efficacy for these cancers represent an unmet need. One of the actionable signaling pathways is the fibroblast growth factor receptor (FGFR) signaling pathway. Several mutations and alterations in FGF/FGFR family members have been reported in human cancers. FGF/FGFR signaling pathway has become a new target for cancer therapy. This review will summarize the role of FGFR pathway and the genetic alterations of the FGF/FGFR related to female reproductive system cancer. We will describe the available inhibitors of FGFR pathway for potential treatment of female reproductive system cancer. Furthermore, we will discuss FGFR-targeted therapies under clinical development for treatment of female reproductive system cancer.
\end{abstract}

Key words: Fibroblast growth factor; Fibroblast growth factor receptor; Genetic variations; Therapeutic targets; Female reproductive system cancer

\section{Introduction}

Endometrial cancer, ovarian cancer and cervical cancers are three relatively common malignant tumors of the female reproductive system. Endometrial cancer that accounts for more than 95\% of cases of uterine cancer is one of the most prevalent forms of gynecological cancers. It is thought to be caused by increasing estrogen levels relative to progesterone in the body. Endometrial cancer at stages I and II responds well to surgical interventions, but the disease at stages III and IV has poor prognosis with low survival rates. Ovarian cancer is the third leading gynecological malignancy worldwide and carries the highest mortality. Most ovarian cancers initiated from epithelial cells and are thus composed of poorly differentiated epithelial cells [1]. Cervical cancer has the fourth greatest global burden of cancer among women for both incidence and mortality [2].
WHO estimated that 570,000 new cases occurred and 311,000 women died from cervical cancer globally in 2018, with nearly $90 \%$ of these deaths occurring in low-income and middle-income countries [3]. Cervical cancer is caused by infection with high-risk genotypes of human papillomavirus (HPV). Despite improvements in female genital tract cancer detection and development of new therapeutic approaches, there are still poor prognosis and non-response to therapeutic patterns, displaying low survival and high frequency of recurrence. Therefore, it is especially necessary for early diagnosis, treatment and survival of cancer patients to find specific biomarkers and drug targets for female reproductive system cancer.

Fibroblast growth factor receptors (FGFRs) are a family of receptor tyrosine kinase (RTKs) encoded by 
four different genes (FGFR1-4), among them, FGFR1-FGFR3 generate two major splice variants of immunoglobulin-like domain III, referred to as IIIb and IIIc, which are essential determinants of ligandbinding specificity [4]. The signaling of FGFR axes is involved in cell proliferation, differentiation, tissue modeling, and angiogenesis via gene amplification, overexpression, point mutations or chromosomal translocations, which can lead to the development and/or progression of cancer [5]. In the last few years, numerous studies have uncovered increasing evidence that FGFRs are driving oncogenes in certain cancers and act in a cell autonomous fashion to maintain the malignant properties of tumor cells. These observations make FGFRs increasingly attractive as targets for therapeutic intervention in cancer. Since FGFR inhibition can reduce proliferation and induce cell death in a variety of in vitro and in vivo tumor models harboring FGFR aberrations, an increasing number of researchers have selected FGFRs as targets for anticancer drug development [5].

Some of the most striking clinical findings regarding FGFRs relate to how these receptors are implicated in female genital tract cancers. In this article, we describe recent advances of FGFR signaling pathway in endometrial, ovarian and cervical carcinogenesis and progression. Moreover, we highlight the genetic variations (including somatic mutation and gene amplification) of FGF or FGFR family members and summarize the FGFR-targeted therapies under clinical development for treatment female genital tract cancers.

\section{FGF/FGFR signaling pathway}

FGFRs in response to fibroblast growth factors (FGFs) transmit signals. The FGF family belongs to a large family of growth factors with significant expression profiles in the female reproductive tract and potentially important roles on fertility. This family is composed of 18 secreted proteins that are grouped into 5 subfamilies according to sequence homology [6,7]. Both FGFs and FGFRs are involved in different physiologic processes, such as regulation of angiogenesis, embryonic development, and wound repair, among others. Additionally, the FGF/FGFR signaling network plays a critical role in cancer cell proliferation, survival, differentiation, migration, and apoptosis [8-10].

Notably, dysregulation of the FGFR pathway is associated with various human cancers and is considered as an oncogenic signaling pathway $[8,11]$. In recent large-scale high-throughput studies, the dysregulation of FGFRs was detected in over $7 \%$ of cancers [12]. FGFRs activated the propagation of signals through the receptor tyrosine kinase-mediated phosphorylation of the adaptor proteins of the pivotal cellular signaling pathways [13]. The complex downstream signaling including the mitogen activated protein kinase (MAPK) [14], phospholipase $\mathrm{C}_{Y}$ (PLCY) [15], signal transducer and activator of transcription (STAT), phosphoinositide 3-kinase (PI3K)/protein kinase B (AKT)/mammalian target of rapamycin (mTOR), and Ras-Raf-MEK-ERK pathway [16-19]. FGFR substrate 2F (FRS2) is a key adaptor protein that associates with the receptor and initiates downstream signaling. The phosphorylation of FRS2 by FGFRs stimulates the binding of the growth factor receptor bound-2 (GRB2) protein to FRS2. GRB2 propagates signals through the two major signaling pathways: PI3K/AKT/mTOR and Ras-Raf-MEK-ERK (Figure 1).

\section{The cellular mechanisms of FGFR signaling}

FGF/FGFR signaling governs fundamental cellular processes such as cell survival, proliferation, migration, differentiation, embryonic development, organogenesis, tissue repair/regeneration, and metabolism [10, 20, 21]. Notably, FGFR2 expression has been reported to be associated with cell growth and progression of cervical dysplasia [22, 23]. FGFRs recruit stromal cells, which are essential participants in the growth and motility of ovarian cancer cells.

\section{The molecular mechanisms of FGFR signaling}

Genetic variations, especially SNPs, and genomic alterations, such as gene amplification, chromosomal translocation, and point mutation, are involved in the transcriptional upregulation of FGFR mRNAs and the functional activation of FGFR proteins during carcinogenesis (Figure 2). Recent study suggested that the fibroblast FGF/FGFR family could interact with PI3K/AKT pathway and subsequently involve in the carcinogenesis of ovarian cancer. In endometrial cancer cell lines, loss of PTEN has been suggested as apotential mechanism of resistance to FGFR inhibition [71]. Noticeably, co-treatment of FGFR2 and mTOR has a synergistic effect on the growth of endometrial cancer cell lines bearing an activating FGFR2 mutation, irrespective of PTEN status.

\section{FGFR signaling as a hot target for the development of anti-tumor drugs in clinical}

In clinical, although anti-FGFR therapy represents a promising targeted cancer treatment, early phase clinical trials have had mixed success, with response to therapy dependent on several factors, including cancer type, tumor histology, and presence or absence of certain biomarkers [24]. An increasing number of drugs against the FGF pathways is currently in clinical testing. Previous study revealed that combined inhibition of mTOR and FGFR 
signaling could be a promising anticancer approach [25]. Choi et al. [26] investigated the clinical significance of FGFR1, FGFR2, FGFR3 and FGFR4 expression in a well-defined cohort of cervical cancers. One important conclusion is that a high expression of FGFR2, FGFR3, and FGFR4 showed longer disease-free survival and overall survival. In recent years, a large number of studies have confirmed that blocking FGF-FGFR-mediated tumor signaling pathway can effectively inhibit tumor proliferation and metastasis. Therefore, FGFR has become a hot target for the development of anti-tumor drugs. FGFR tyrosine kinase inhibitors (TKIs) have been undergoing Phase I/II clinical trials, but no inhibitors specifically targeting FGFRs have been marketed or used clinically. Since most of the kinase domains are highly similar, the first generation of FGFR TKIs (non-selective FGFR mainly including dovitinib, lucitanib, lenvatinib, ponatinib and nintedanib) generally inhibit various kinases other than FGFR (such as VEGFRs, PDGFRs, etc.). These non-selective inhibitors usually cause large toxic side effects and are greatly limited in practical applications. Second-generation FGFR inhibitors such as AZD4547, JNJ-42756493, BGJ-398 and LY2874455 have higher FGFR selectivity than first-generation inhibitors and are expected to produce higher levels of clinical benefit and reduce the risk of adverse reactions. At present, it has been found that selective inhibitors of FGFR4 (BLU554, H3B-6527 and FGF401) can effectively treat liver cancer, and can avoid some side effects caused by multi-target inhibitors. However, these drugs are still in the clinical research stage and have not been approved for clinical use by the FDA. In the context of low-frequency molecular aberrations, Prospective selection of patients with specific FGFR aberrations is one of the major challenges in clinical trials. However, molecular screening is therefore a crucial challenge for the development of FGFR inhibitors as patient selection is a key in this context (Figure 3). The main challenges have included (i) determining optimal diagnostic procedures for FGFR molecular alterations, and standardizing the definition of FGFRs amplification; (ii) detecting rare-frequency fusion genes involving various partners; (iii) discriminating between passenger and driver alterations; (iv) integrating the available information within a specific cellular and tumor heterogeneity context.

\section{FGFR signaling in female reproductive system cancer}

\section{Cervical cancer}

Cervical cancer is the fourth most common female malignancy worldwide. Each year, more than half a million women are diagnosed with cervical cancer and the disease results in over 300,000 deaths worldwide [27]. Compared with the most affluent counties, mortality rates in the poorest counties were 2-fold higher for cervical cancer [28]. The most common risk factor for the development of cervical cancer is chronic infection by oncogenic human papilloma virus (HPV), such as HPV16 and HPV18 viruses [29]. Recently years, cervical cancer continues to be the second leading cause of cancer death in women aged 20 to 39 years, which underscores the need for increased HPV vaccination uptake in adolescents and guideline-adherent screening in young women [28].

The oncogenic significance role of the FGFRs has been elucidated in cervical cancer. Choi et al. [26] investigated the immunohistochemical expression of FGFR1, FGFR2, FGFR3, and FGFR4 in 336 cervical cancer patients, and confirmed that FGFR2, FGFR3, and FGFR4 expressions were important prognostic indicators in cervical cancer. Recent studies have shown the possible involvement of aberrant FGFR signaling with HPV16 E5 expression [30]. FGFR2 expression has been reported to be associated with cell growth and progression of cervical dysplasia. The FGFR3-TACC3 fusion gene has been detected in uterine cervical cancer [22, 23]. Recent study has identified four samples that harbored FGFR3-TACC3 fusion as an attractive therapeutic target through analyzing RNA sequencing data from 306 cervical cancer samples [31]. However, FGFR2 and FGFR3 mutations are rarely detected in cervical cancer [32, 33].

\section{Ovarian cancer}

Ovarian cancer is the leading cause of death from gynecologic cancers [34]. Advanced ovarian cancer remains an unmet clinical need. Compared with current treatments, potential targeted therapies could be more effective. Recent study suggested that the FGF/FGFR pathway can interact with PI3k/AKT pathway involved in the carcinogenesis of ovarian cancer [35]. Individual FGFRs including FGFR2 IIIb are over-expressed in ovarian cancer [36]. Taniguchi $F$ et al. [37] found that up-regulated FGFR2 expression has been shown to be potentially involved in the transformation of ovarian endometrioma to clear cell carcinoma of the ovary. Although FGFR2 mutations are considered rare in ovarian cancer, the Ser252Trp mutation seen in endometrial cancer has also been detected in the ovary cancer [38], suggesting a loss of ligand specificity for FGF signaling in at least some ovarian cancers. 


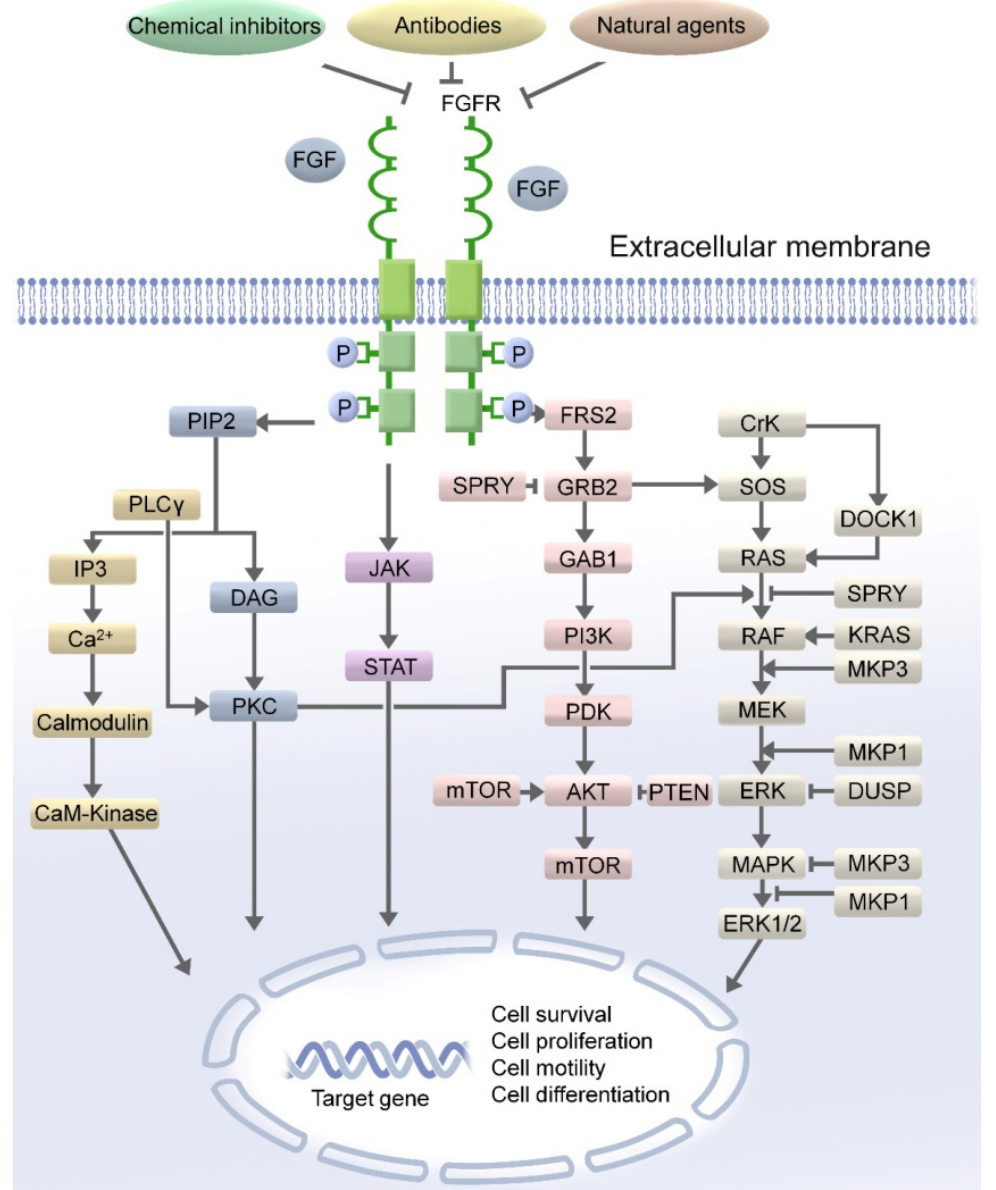

Figure 1. The FGF/FGFR signaling pathway. FGF/FGFR exhibits its physiological functions by regulating the main downstream signaling pathway, such as RAS/MAPK and PI3K/AKT/mTOR, FGF/FGFR signaling pathway could be blocked by the chemical inhibitors of FGF/FGFR, antibodies and natural agents. Therefore, targeting FGF/FGFR pathway could be an effective approach for the treatment of female reproductive system cancer patients.
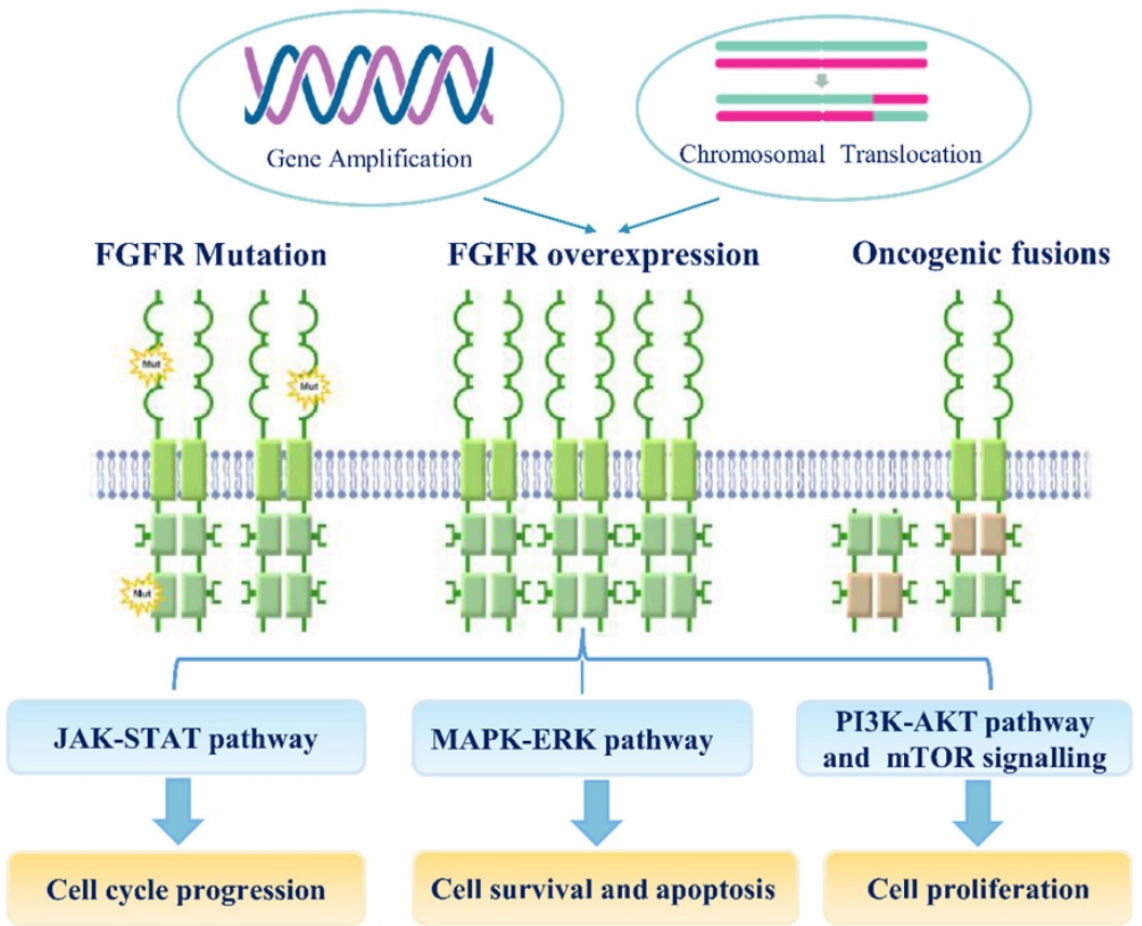

Figure 2. The mechanisms of FGF/FGFR signaling dysregulation. Enhanced FGFR signaling dysregulation is mediated by genetic alterations (Gene amplification, FGFR mutations, chromosomal translocations and gene fusions).FGFR over-expression by gene amplification or chromosomal translocation. FGF/FGFR signaling dysregulation can activate JAK/STAT, MAPK/ERK, PI3K-AKT and mTOR signaling pathways; these signaling can regulate multiple cellular processes, including cell survival, proliferation, motility apoptosis and so on. 


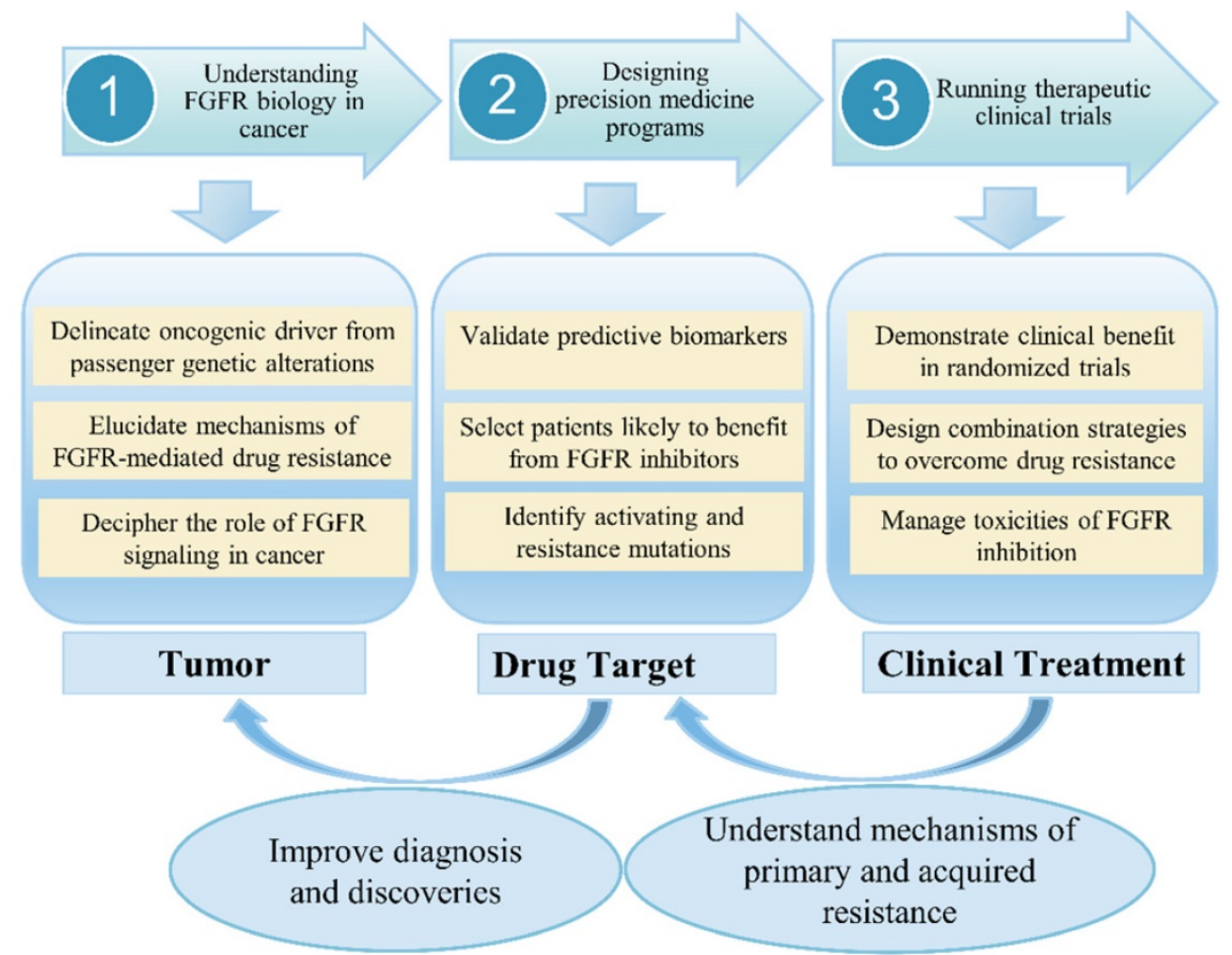

Figure 3. FGFR signaling research from bench to bedside in cancer. The challenges and prospects for the development of FGFR-targeted therapies.

FGFR4 is a prognostic marker for advancedstage, high-grade serous ovarian cancer. Experiments in vitro and in vivo have shown that silencing FGFR4 and inhibiting ligand-receptor binding significantly decreased the proliferation, survival, and invasiveness and increased apoptosis of ovarian cancer cells, suggesting that FGFR4 protein expression is a new therapeutic modality for this disease and will improve its survival in clinical trials [39]. High levels of FGFR4 protein have been reported in serous ovarian carcinomas and were associated with poor patient survival [39], although the ligand involved was suggested to be FGF19 [40]. On the other hand, a Gly388Arg mutation in FGFR4 has been reported in ovarian cancer and was associated with increased patient survival [41].

\section{Endometrial cancer}

Endometrial cancer is the most common gynecologic malignancy among women in developed countries, with an estimated 63,230 new cases in 2018 [42]. Most patients are peri-and post-menopausal. In spite of the relative survival of 5 years is high for patients diagnosed with early-stage endometrial cancer, however, there are few treatment methods for patients who present with metastatic or recurrent endometrial cancer, and the prognosis of such patients remains poor. Recently, molecular targeted therapies have shown promising results in the management of endometrial cancer. FGFR pathway is one of pathways related to the pathogenesis and progress of endometrial cancer [43]. FGFR alterations reported in endometrial cancers most frequently involve FGFR2 [12]. According to The Cancer Genome Atlas (TCGA) data reported in Nature in 2013, the most frequently altered FGFR gene in endometrial cancers was FGFR2, with $12.5 \%$ of sequenced samples $(\mathrm{n}=248$ samples) harboring alterations in this gene. Recently, several independent studies have identified FGFR2 mutations in endometrial cancer [44-46]. FGFR2 is thought to be a potential therapeutic molecular target for patients with FGFR2 activationassociated endometrial cancer. In endometrial cancer cell lines harboring activating FGFR2 mutations, inhibition of FGFR kinase activity inhibited cell cycle progression, cell survival, and colony formation. In vivo experiment has shown that FGFR inhibitor decreased the growth of FGFR2-mutated endometrial cancer xenograft models [44, 47]. As the FGFR small-molecule inhibitor PD173074 diminishes survival and anchorage-independent growth by endometrial cancer cell lines expressing activating FGFR2 mutations [44]. Previous studies have revealed that combined inhibition of mTOR and FGFR signaling could be a promising anticancer approach in endometrial cancer [25]. 


\section{The genetic variations and somatic mutations of FGF/FGFR pathway}

The FGF/FGFR signaling pathway is frequently deregulated in human cancers. Over the last years, several mutations and alterations in FGF-FGFR pathway have been reported in cancer [48]. Helsten et al. [12] sequenced 4853 tumor tissue samples, and found that $7.1 \%$ of all samples had genetic alterations in the FGF-FGFR axis. We summarized the germline genetic alterations (amplification and Singlenucleotide polymorphisms) as well as somatic changes (somatic mutation and somatic copy number alterations) of FGF and FGFR family members in Table 1.

Table 1. Genetic variations and somatic mutations of FGF and FGFR family genes in female reproductive system cancers

\begin{tabular}{|c|c|c|c|c|c|}
\hline Gene & Cancer type & $\begin{array}{l}\text { Germline } \\
\text { or somatic }\end{array}$ & $\begin{array}{l}\text { Genetic } \\
\text { changes }\end{array}$ & Mutations SNPs & Refs \\
\hline FGFR1 & Ovarian cancer & Somatic & $\begin{array}{l}\text { Gene } \\
\text { amplification }\end{array}$ & & {$[85]$} \\
\hline FGFR1 & $\begin{array}{l}\text { Endometrial } \\
\text { Cancer }\end{array}$ & Somatic & $\begin{array}{l}\text { Gene } \\
\text { amplification }\end{array}$ & & [86] \\
\hline FGFR2 & $\begin{array}{l}\text { Endometrial } \\
\text { cancer }\end{array}$ & Somatic & $\begin{array}{l}\text { Missense } \\
\text { mutation }\end{array}$ & $\begin{array}{l}\text { D101Y, S252W, } \\
\text { P253R, C382R, } \\
\text { N549K, N550K, } \\
\text { L764fs*4 }\end{array}$ & $\begin{array}{l}{[44,45,} \\
87-92]\end{array}$ \\
\hline FGFR2 & Cervical cancer & Somatic & $\begin{array}{l}\text { Missense } \\
\text { mutation }\end{array}$ & K660M & {$[44,93]$} \\
\hline FGFR2 & Ovarian cancer & Germline & SNPs & $\begin{array}{l}\text { rs4752566, } \\
\text { rs2981582, } \\
\text { rs3135830, } \\
\text { rs2981451, } \\
\text { rs3135826, } \\
\text { rs2912759 }\end{array}$ & [55] \\
\hline FGFR3 & Cervical cancer & Somatic & $\begin{array}{l}\text { Missense } \\
\text { mutation }\end{array}$ & S249C & {$[61]$} \\
\hline FGFR3 & Ovarian cancer & Somatic & $\begin{array}{l}\text { Gene } \\
\text { amplification }\end{array}$ & & {$[12]$} \\
\hline FGFR4 & Cervical cancer & Germline & SNP & rs351855 & [56] \\
\hline FGF2 & Ovarian cancer & Germline & SNPs & rs167428, rs308441 & [55] \\
\hline FGF2 & $\begin{array}{l}\text { Endometrial } \\
\text { cancer }\end{array}$ & Germline & SNPs & $754 \mathrm{C} / \mathrm{G}$ & [54] \\
\hline FGF23 & Ovarian cancer & Germline & SNPs & $\begin{array}{l}\text { rs7961824, } \\
\text { rs12812339 }\end{array}$ & [55] \\
\hline FGF1 & Ovarian cancer & Germline & SNPs & $\begin{array}{l}\text { rs7727832, } \\
\text { rs2052006, } \\
\text { rs10070885. } \\
\text { rs17099029 }\end{array}$ & [55] \\
\hline
\end{tabular}

\section{FGFR genetic alteration in female reproductive system cancer}

Previous studies of germline FGFR mutations indicate that point mutations can result in differential localization and signaling [49-53]. Single Nucleotide Polymorphisms (SNPs) of FGF or FGFR are associated with increased risk of female reproductive system cancer [54-57]. Somatic mutations in FGFR1, FGFR2, FGFR3, and FGFR4 genes are reported in endometrial cancer. FGFR1 and FGFR3 amplifications are also found in endometrial cancer through integrating genomic characterization of somatic copy number alterations [58]. FGFR2 mutations are the most frequent genomic aberration and have been found in $10-12 \%$ of endometrial carcinomas [12, 44]. Activating FGFR2 mutation could be an important therapeutic target for endometrial cancers. Decreased cancerspecific survival is also seen in a multi-institutional cohort of over 950 endometrial cancer patients with somatic FGFR2 mutations, irrespective of stage [59]. Furthermore, the copy number of FGFR1 was elevated both in endometrioid carcinoma and ovarian cancer [60]. Mutations in FGFR3 are found in around $5 \%$ of cervical cancers [61,62]. Gene amplification in FGFR1, point mutation in FGFR2, and genetic alterations in FGFR3 are relatively frequent in ovarian and uterine cancer [12]. Somatic mutations of the FGFR3 gene encompass the extracellular and transmembrane domains of the protein [63]. To investigate oncogenic genetic alterations in cervical cancer, Xiang et al. [64] examined the mutational status of 16 oncogenic genes, such as FGFR2 and FGFR3 as well as FGFR3-TACC3, FGFR1-TACC1 fusions in a cohort of 285 Chinese patients with resected cervical cancer. Li et al. [56] found that FGFR4 gene polymorphism rs351855 (Glu388Arg) was associated with the prognosis of high-risk HPV infection cervical cancer, and the risk of worse prognosis inpatients with allele A was higher than that of GG patients.

\section{FGF genetic variation in female reproductive system cancer}

Besides FGFR aberrations, a number of studies have also shown that genetic variations of FGF are associated with the disease. Take FGF2 for example, our group previously found that the polymorphisms of FGF2 gene are significantly associated with obesity and osteoporosis in Chinese population [65, 66]. Meng et al. [55] investigated the genetic variants in FGF-FGFR pathway for associations with risk of ovarian cancer, therapeutic and overall survival. They revealed FGF2 rs167428 as the primary factor contributing to overall survival. FGF23 rs7961824 showed the most significant association with ovarian cancer survival. This provides a molecular approach for monitoring therapeutic response, and prediction of cancer diagnosis.

\section{FGFRs as therapeutic targets}

Since FGF/FGFR signaling plays a crucial role in cancers, a variety of small molecule FGFR inhibitors target FGF/FGFR signaling pathway have been developed and shown significant therapeutic effects in pre-clinical and clinical studies [14]. FGFR inhibitors function as tumor suppressors, therefore, more efforts have been focused on developing the inhibitors to target FGFRs, which show particular 
promise as an anticancer monotherapy or an adjunct treatment. There are mainly two kinds of FGFR inhibitors in clinical trials, including non-selective FGFR TK inhibitors (TKIs) and selective FGFR TKIs. Another two anti-FGF/FGFR agents are neutralizing monoclonal antibodies (mAbs) and FGF ligand traps.

\section{Non-selective FGFR TKIs}

Actually, the most clinically advanced compounds are non-selective TKIs, such as brivanib, dovitinib, lenvatinib, ponatinib, nintedanib, and cediranib. Most of these inhibitors target ATP binding pocket in the TK domains of FGFRs through reversible or covalent bonds [67]. For example, ponatinib can impede the autophosphorylation activity of FGFRs by binding to the hinge region of FGFRs and block the ATP-binding cassette motif [68]. Several TKIs which target the FGFR pathway have shown preclinical activity $[25,47,69]$.

To date, the most clinically advanced FGFR TKIs in FGFR targeted treatment is dovitinib (TKI258), which is now being tested in endometrial cancer patients with FGFR2 mutation (NCT01379534). Brivanibis another dual TKI against FGFRs and VEGFRs, which was found to be effective in metastatic solid malignancies resistant to standard therapy and is currently being developed as an anti-angiogenic agent in Phase II clinical trials [70]. Lenvatinib (E7080) shows inhibitory activity against
VEGFRs, FGFRs and PDGFRs, which is being tested in Phase II clinical trials, examining the efficacy in patients with metastatic endometrial cancer (NCT01111461) [71, 72]. Nintedanib (BIBF 1120) is an orally administered triple angio-kinase inhibitor of the receptors of VEGFR-1-3, PDGFR-a/b and FGFR-1-3 [73].

AL3818 (anlotinib) is a receptor tyrosine kinase inhibitor targeting vascular endothelial growth factor receptors (VEGFR1, VEGFR2/KDR, and VEGFR3), stem cell factor receptor (C-kit), platelet-derived growth factor (PDGFA), and fibroblast growth factor receptors (FGFR1, FGFR2, and FGFR3). This study evaluates the efficacy of AL3818 studying tumor regression in endometrial cancer model [74].

Several other TKIs are also summarized in Table 2, including cediranib, ponatinib, ENMD2076, pazopaniband regorafenib, which have been developed and are in pre-clinical and clinical evaluation [75]. However, almost all of these non-selective compounds induce a series of toxic effects, such as cardiotoxicity or proteinuria due to the concurrent VEGFR inhibition, cutaneous reactions, digestive disorders, and gastrointestinal diseases [24]. As far as we know, there is no information about its activity against FGFR, therefore, a new clinical trial has been initiated with the aim of more substantial proof (Table 2).

Table 2. Non-selective FGFR tyrosine kinase inhibitors of female reproductive system cancer. Known targets, cancer type, clinical trials identifier FGFR criteria, phase and clinical trials involving multi-target TKIs with FGFR status bases patient selection are indicated for each compound. Data were collected at clinicaltrials.gov, cancer.gov and PubMed

\begin{tabular}{|c|c|c|c|c|c|c|}
\hline Compound & Target & Cancer type & $\begin{array}{l}\text { Clinical trial } \\
\text { identifier }\end{array}$ & FGFR Criteria & Phase & Status \\
\hline \multirow{2}{*}{$\begin{array}{l}\text { Dovitinib } \\
\text { (TKI258) }\end{array}$} & \multirow{2}{*}{$\begin{array}{l}\text { FGFR3, VEGFR1/3, FGFR1, } \\
\text { PDGFR3, }\end{array}$} & Endometrial Cancer & NCT01379534 & FGFR2 mutation & II & Completed \\
\hline & & Ovarian Cancer & NCT01831726 & $\begin{array}{l}\text { FGFR 1-3 mutations } \\
\text { or amplifications }\end{array}$ & II & Completed \\
\hline \multirow{13}{*}{$\begin{array}{l}\text { Nintedanib } \\
\text { (BIBF 1120) }\end{array}$} & \multirow[t]{13}{*}{ VEGFR, FGFR, PDGFR } & \multirow[t]{2}{*}{ Endometrial Cancer } & NCT02730416 & & II & Recruiting \\
\hline & & & NCT01225887 & & II & Completed \\
\hline & & \multirow[t]{9}{*}{ Ovarian Cancer } & $\begin{array}{l}\text { NCT01485874 } \\
\text { NCT01329549 }\end{array}$ & & I & Terminated \\
\hline & & & NCT01610869 & & II & $\begin{array}{l}\text { Active, not } \\
\text { recruiting }\end{array}$ \\
\hline & & & NCT01583322 & & II & Completed \\
\hline & & & NCT00710762 & & & \\
\hline & & & NCT01669798 & & & \\
\hline & & & NCT01314105 & & I & Completed \\
\hline & & & NCT02835833 & & & \\
\hline & & & NCT01015118 & & III & Completed \\
\hline & & & NCT02866370 & & II & Recruiting \\
\hline & & \multirow[t]{2}{*}{ Cervical Cancer } & NCT02009579 & & II & Recruiting \\
\hline & & & NCT02835833 & & I & Completed \\
\hline \multirow[t]{3}{*}{$\begin{array}{l}\text { Brivanib } \\
\text { (BMS-582664) }\end{array}$} & \multirow[t]{3}{*}{ VGFR1-3, FGFR1-3 } & Endometrial Cancer & NCT00888173 & $\begin{array}{l}\text { FGFR2 activation } \\
\text { mutation }\end{array}$ & II & Completed \\
\hline & & Ovarian Cancer & NCT03895788 & & I & Recruiting \\
\hline & & Cervical Cancer & NCT01267253 & & II & Completed \\
\hline $\begin{array}{l}\text { Ponatinib } \\
\text { (AP24534) }\end{array}$ & VEGFR2-3, FGFR1-2 & Endometrial Cancer & NCT01888562 & FGFR2 mutation & Not Applicable & Withdrawn \\
\hline \multirow[t]{2}{*}{ Lenvatinib (E7080) } & \multirow[t]{2}{*}{ VEGFR2, FGFRs, PDGFRs } & \multirow[t]{2}{*}{ Endometrial Cancer } & NCT01111461 & & II & Completed \\
\hline & & & NCT03517449 & & III & Recruiting \\
\hline
\end{tabular}




\begin{tabular}{|c|c|c|c|c|c|c|}
\hline Compound & Target & Cancer type & $\begin{array}{l}\text { Clinical trial } \\
\text { identifier }\end{array}$ & FGFR Criteria & Phase & Status \\
\hline & & & NCT03884101 & & & \\
\hline & & & NCT03005015 & & II & Withdrawn \\
\hline & & & NCT03006887 & & & recruiting \\
\hline & & Ovarian Cancer & NCT01133756 & & I/II & Terminated \\
\hline & & & NCT02788708 & & I & $\begin{array}{l}\text { Active, not } \\
\text { recruiting }\end{array}$ \\
\hline & & & NCT03797326 & & II & Recruiting \\
\hline \multirow{15}{*}{$\begin{array}{l}\text { Cediranib } \\
\text { (AZD2171) }\end{array}$} & VEGFR1-3, FGFRs & Endometrial Cancer & NCT03660826 & & II & Recruiting \\
\hline & & & NCT03570437 & & & \\
\hline & & & NCT01132820 & & II & Completed \\
\hline & & & NCT01065662 & & I & $\begin{array}{l}\text { Active, not } \\
\text { recruiting }\end{array}$ \\
\hline & & Ovarian Cancer & NCT02889900 & & II & Active, not \\
\hline & & & NCT03314740 & & & recruiting \\
\hline & & & NCT02340611 & & II & Completed \\
\hline & & & NCT00278343 & & & \\
\hline & & & NCT00275028 & & & \\
\hline & & & NCT00532194 & & III & Unknown \\
\hline & & & NCT02681237 & & Not Applicable & Recruiting \\
\hline & & & NCT03278717 & & III & Recruiting \\
\hline & & & NCT03117933 & & II & Recruiting \\
\hline & & & NCT03699449 & & & \\
\hline & & & NCT02855697 & & Early Phase 1 & Recruiting \\
\hline \multirow[t]{6}{*}{$\begin{array}{l}\text { Cediranib } \\
\text { (AZD2171) }\end{array}$} & VEGFR1-3, FGFRs & Ovarian Cancer & $\begin{array}{l}\text { NCT01131234, } \\
\text { NCT00475956 }\end{array}$ & & I & Completed \\
\hline & & & NCT01065662 & & I & $\begin{array}{l}\text { Active, not } \\
\text { recruiting }\end{array}$ \\
\hline & & & NCT01116648 & & $\mathrm{I} / \mathrm{II}$ & $\begin{array}{l}\text { Active, not } \\
\text { recruiting }\end{array}$ \\
\hline & & & NCT02446600 & & III & $\begin{array}{l}\text { Active, not } \\
\text { recruiting }\end{array}$ \\
\hline & & Cervical Cancer & NCT01065662 & & $\mathrm{I}$ & $\begin{array}{l}\text { Active, not } \\
\text { recruiting }\end{array}$ \\
\hline & & & NCT01229930 & & II & Completed \\
\hline \multirow[t]{2}{*}{ ENMD2076 } & FGFR1-2, PDGFRs, VGFR2 & Ovarian Cancer & NCT01104675 & & II & Completed \\
\hline & & & NCT01914510 & & II & Completed \\
\hline \multirow{14}{*}{$\begin{array}{l}\text { Pazopanib } \\
\text { (GW786034) }\end{array}$} & VEGFR1-3, PDGFR, FGFR1/3 & Ovarian Cancer & NCT01600573 & & I/II & Unknown \\
\hline & & & NCT01402271 & & & \\
\hline & & & NCT01238770 & & $\mathrm{I} / \mathrm{II}$ & Completed \\
\hline & & & NCT02383251 & & II & Active, not \\
\hline & & & NCT01610206 & & & recruiting \\
\hline & & & NCT01608009 & & I & Completed \\
\hline & & & NCT01262014 & & II & Completed \\
\hline & & & NCT01644825 & & & \\
\hline & & & NCT00281632 & & & \\
\hline & & & NCT01468909 & & & \\
\hline & & & NCT01227928 & & & \\
\hline & & & NCT00561795 & & & \\
\hline & & & NCT02055690 & & I/II & Terminated \\
\hline & & & NCT01035658 & & & \\
\hline \multirow{6}{*}{$\begin{array}{l}\text { Pazopanib } \\
\text { (GW786034) }\end{array}$} & VEGFR1-3, PDGFR, FGFR1/3 & Ovarian Cancer & NCT00866697 & & III & Completed \\
\hline & & & NCT01392352 & & II & Terminated \\
\hline & & & NCT02009449 & & I & $\begin{array}{l}\text { Active, not } \\
\text { recruiting }\end{array}$ \\
\hline & & Cervical Cancer & NCT02348398 & & II & Withdrawn \\
\hline & & & NCT00430781 & & II & Completed \\
\hline & & & NCT01392352 & & II & Terminated \\
\hline \multirow{4}{*}{$\begin{array}{l}\text { Regorafenib } \\
\text { (BAY73-4506) }\end{array}$} & VEGFR1-3,PDGFR $\beta$, FGFRs & Ovarian Cancer & NCT02278783 & & II & Terminated \\
\hline & & & NCT02736305 & & II & Recruiting \\
\hline & & & NCT02584465 & & & \\
\hline & & & NCT02307500 & & & \\
\hline Anlotinib (AL3818) & VEGFR1-3, PDGFR- $\alpha$, FGFR1-3 & Endometrial Cancer & NCT02558348 & FGFR1, FGFR2 or 3 & $\mathrm{I} / \mathrm{II}$ & Recruiting \\
\hline
\end{tabular}




\begin{tabular}{|c|c|c|c|c|c|c|}
\hline \multirow[t]{6}{*}{ Compound } & Target & Cancer type & $\begin{array}{l}\text { Clinical trial } \\
\text { identifier }\end{array}$ & FGFR Criteria & Phase & Status \\
\hline & & Ovarian Cancer & NCT03924882 & & II & Recruiting \\
\hline & & & NCT02558348 & $\begin{array}{l}\text { FGFR1, } 2 \text { or } 3 \\
\text { amplification or } \\
\text { mutation }\end{array}$ & $\mathrm{I} / \mathrm{II}$ & Recruiting \\
\hline & & & NCT02584478 & & $\mathrm{I} / \mathrm{II}$ & Recruiting \\
\hline & & Cervical Cancer & NCT02558348 & $\begin{array}{l}\text { FGFR1, } 2 \text { or } 3 \\
\text { amplification or } \\
\text { mutation }\end{array}$ & $\mathrm{I} / \mathrm{II}$ & Recruiting \\
\hline & & & NCT02584478 & & I/II & Recruiting \\
\hline
\end{tabular}

Note: FGF, fibroblast growth factor; FGFR, fibroblast growth factor receptor; VGFR, vascular growth factor receptor; VEGFR, vascular endothelial growth factor; PDGFR, platelet-derived growth factor receptor.

Table 3. Selective FGFR TKIs, ligand trap and mAbs of female reproductive system cancer

\begin{tabular}{|c|c|c|c|c|c|c|}
\hline Compound & Target & Cancer type & Clinical trial identifier & FGFR Criteria & Phase & Status \\
\hline \multicolumn{7}{|c|}{ Selective FGFR TKIs } \\
\hline AZD4547 & FGFR1-3 & $\begin{array}{l}\text { Endometrial Cancer; Ovarian Cancer; } \\
\text { Cervical Cancer }\end{array}$ & NCT02465060 & $\begin{array}{l}\text { FGFR1-3 mutation or } \\
\text { translocation }\end{array}$ & III & Recruiting \\
\hline BGJ398 & FGFR1-3 & Cervical Cancer & NCT02312804 & & I & Withdrawn \\
\hline $\begin{array}{l}\text { Erdafitinib } \\
\text { (JNJ-42756493) }\end{array}$ & FGFR1-4 & $\begin{array}{l}\text { Endometrial Cancer; Ovarian Cancer; } \\
\text { Cervical Cancer }\end{array}$ & NCT02465060 & $\begin{array}{l}\text { FGFR amplification/ } \\
\text { mutation or fusion }\end{array}$ & II & Recruiting \\
\hline \multicolumn{7}{|c|}{ FGF and traps and mAbs } \\
\hline $\begin{array}{l}\text { FP-1039 } \\
(\text { GSK3052230) }\end{array}$ & FGF2 & Endometrial Cancer & NCT01244438 & FGFR2 mutation & II & Withdrawn \\
\hline PRO-001 & $\begin{array}{l}\text { FGFR3-specific } \\
\text { blocking antibody }\end{array}$ & Cervical Cancer & NCT01263327 & & I & Completed \\
\hline
\end{tabular}

\section{Selective FGFRs TKIs}

AZD4547 is a famous selective TKI that specific target for FGFRs (FGFR1-3) [76]. The inhibitory activity of AZD4547 has been demonstrated in vitro and in vivo models of endometrial cancer characterized by FGFR activation due to genetic alteration [77]. BGJ398 is also a selective reversible ATP-competitive FGFR1-3 inhibitor. Its anti-tumor activity was firstly assessed in pre-clinical models of endometrial cancer [47, 78]. The FGFR inhibitors of BGJ398 and AZD4547are mostly in early-phase development programs (Table 3). Phase II trials with genomic enrichment are ongoing. A number of clinical trials use AZD4547 in cancer. One recent finding revealed that combined treatment of BGJ398 and rapamycin may be a promising therapeutic strategy in the treatment of patients with ovarian cancer [25]. They also investigated whether the combined inhibition of mTOR and FGFR pathways would enhance the anticancer effects in the treatment of ovarian cancer. JNJ-42756493 (Erdafitinib) is a highly selective TKIs and shows inhibitory activity against FGFR1-4. Erdafitinib binds the ATP-pocket of the FGFR1 kinase domain with unique structural conformations and its inhibitory efficacy is reduced in the presence of the acquired gatekeeper mutation FGFR3 [79]. JNJ-42756493 suppresses FGFR phosphorylation and downstream signaling [80] and is able to induce stabilization of the disease in advanced solid tumors characterized by FGFR translocations or fusions (such as FGFR3-TACC3).

\section{Monoclonal antibodies and FGF ligand traps}

Anti-FGFR mAbs as well as small molecules acting as traps for the ligands of the FGFR family might represent a new strategy for the treatment of tumors. Based on the identification and characterization of FGF ligands, FGF ligand traps have allowed the development of promising FGF-targeting molecules with potential implications for the therapy of FGF-driven tumors [81]. Since these drugs have higher specificity that may result in a reduced toxicity due to the absence of off-target effects. Whereas, there is only one anti-FGFR mAb (PRO-001) entered clinical trials in female reproductive system cancer. In addition, FP-1039 is a FGF ligand trap and currently in phase II clinical trials to treat endometrial cancer (Table 3). Pre-clinical cancer models with genetic aberrations in the FGFR pathway, including FGFR2-mutated endometrial cancer, are particularly sensitive to FP-1039 mediated tumor inhibition [82].

A large effort to develop FGF/FGFR inhibitors as anticancer treatments is underway. The most clinically advanced anti-FGFR drugs are smallmolecule TKIs, some of them are monoclonal anti-FGFR antibodies and FGF-trapping molecules. Those anti-FGFR drugs that have entered the clinical phases of development are summarized in Figure 4. 


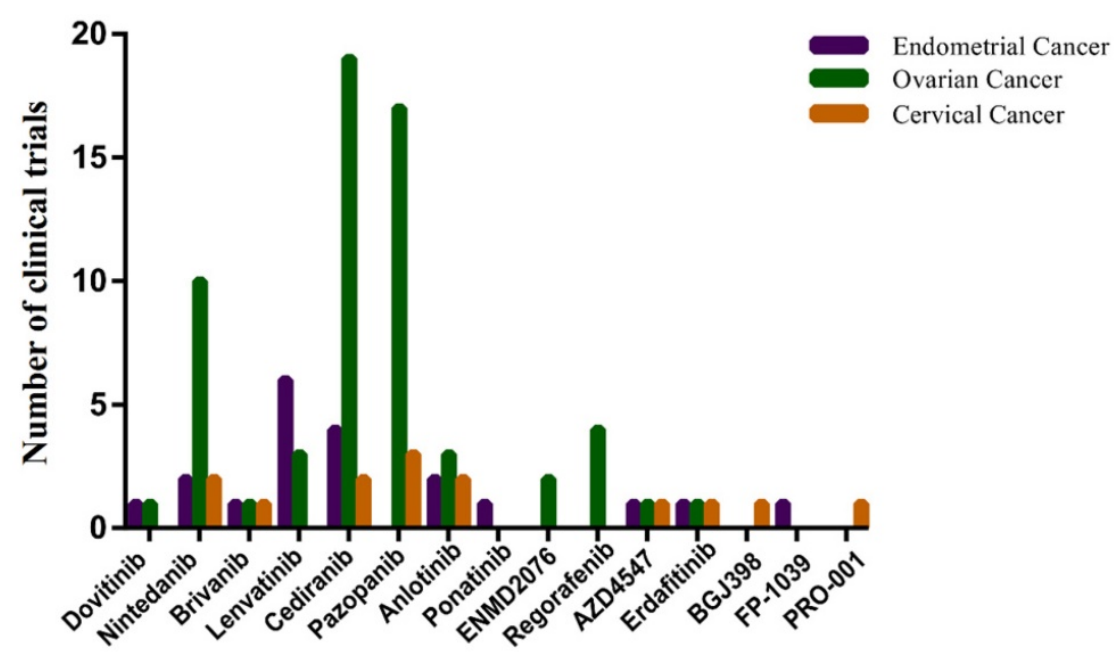

FGFR target agents

Figure 4. The number of clinical trials of FGFR target agents in endometrial cancer, ovarian cancer and cervical cancer. The horizontal axis represents Non-selective TK inhibitors, selective TK inhibitors, mAbs and FGF traps. The vertical axis represents the number of clinical trials. Date sourced from www.clinicaltrails.gov.

\section{Conclusion}

The cancers of the female genital tract represent a leading cause of morbidity and mortality among women worldwide. Undoubtedly, in the past decade, FGF/FGFR signaling therapies are under development for the treatment of gynecologic malignancies as well as in many other solid tumors. Therefore, dissecting canonical FGF/FGFR signaling pathways is still valuable. Deregulation of the FGF/FGFR signaling axis is observed in a wide variety of human cancers [83, 84]. Efforts are needed to recognize patients most likely to benefit from FGFR inhibitors, to validate clinically useful companion diagnostics, to implement combination strategies, to overcome chronic toxicities, and to determine the most clinically relevant compound for registration. Considering the specific FGFR molecular alterations, especially many somatic mutations of FGFRs in female reproductive system cancer type, the experimental determination of which mutations play a causative role in tumorigenesis is currently the rate-limiting step to fully understanding the clinical implications of genomic data.

In conclusion, targeting FGFR is a promising strategy in the treatment of female reproductive system cancer. It is plausible to hope that in the following years the research efforts in pre-clinical and clinical fields allow to establish an optimal treatment strategy in FGFR-addicted female reproductive system cancer population.

\section{Acknowledgments}

This work was supported by the National Natural Science Foundation of China (31771399 and
81573241); Zhejiang Provincial Natural Science Foundation of China (GF18C060003); Major Science and Technology Projects in Xiaoshan District (2018224); China Postdoctoral Science Foundation (2018T111038); Innovative Talent Promotion Plan of Shaanxi Province for Young Sci-Tech New Star (2018KJXX-010); and the Fundamental Research Funds for the Central Universities.

\section{Author Contributions}

D.L.Z. and X.M.T. contributed to editing the manuscript; Y.R. contributed to drawing some figures; K.Z. and Y.G. contributed to reviewing and editing the manuscript. All authors read and approved the final manuscript.

\section{Data Availability Statement}

All data included in this study are available upon request by contact with the corresponding author.

\section{Consent for Publication}

All authors agree to submit for consideration for publication in the journal.

\section{ORCID} 2392.

Yan Guo: https://orcid.org/0000-0002-7364-

\section{Abbreviations}

FGF: Fibroblast Growth Factor; FGFR: Fibroblast Growth Factor Receptor; PI3K: phosphoinositide-3kinase; MAPK: mitogen-activated protein kinase; PKC: protein kinase C; PLC $\gamma$ : phospholipase $\mathrm{C}_{\gamma}$; HPV: human papilloma virus; TCGA: The Cancer Genome Atlas; FRS2: FGFR substrate 2F; GRB2: 
growth factor receptor bound-2; TKI: tyrosine kinase inhibitors; mAbs: Monoclonal antibodies.

\section{Competing Interests}

The authors have declared that no competing interest exists.

\section{References}

1. Romero I, Bast RC, Jr. Minireview: human ovarian cancer: biology, current management, and paths to personalizing therapy. Endocrinology. 2012; 153(4): 1593-1602.

2. Bray F, Ferlay J, Soerjomataram I, et al. Global cancer statistics 2018: GLOBOCAN estimates of incidence and mortality worldwide for 36 cancers in 185 countries. CA Cancer J Clin. 2018; 68(6): 394-424.

3. Arbyn M, Weiderpass E, Bruni L, et al. Estimates of incidence and mortality of cervical cancer in 2018: a worldwide analysis. The Lancet Global health. 2020; 8(2): 191-203.

4. Eswarakumar VP, Lax I, Schlessinger J. Cellular signaling by fibroblast growth factor receptors. Cytokine \& Growth Factor Reviews. 2005; 16(2): 139-149.

5. Ornitz DM, Itoh N. The Fibroblast Growth Factor signaling pathway. Wiley Interdiscip Rev Dev Biol. 2015; 4(3): 215-266.

6. Itoh N, Ornitz DM. Evolution of the Fgf and Fgfr gene families. Trends in Genetics. 2004; 20(11): 563-569.

7. Hui Q, Jin Z, Li X, et al. FGF Family: From Drug Development to Clinical Application. International journal of molecular sciences. 2018; 19(7): 1875

8. Turner N, Grose R. Fibroblast growth factor signalling: from development to cancer. Nature Reviews Cancer. 2010; 10(2): 116-129.

9. J Javier GR, Pilar S, Miguel M, et al. Fibroblast growth factor receptor 3 is overexpressed in urinary tract carcinomas and modulates the neoplastic cell growth. Clinical Cancer Research. 2005; 11(2 Pt 1): 459-465.

10. Tomlinson DC, Lamont FR, Shnyder SD, et al. Fibroblast growth factor receptor 1 promotes proliferation and survival via activation of the mitogen-activated protein kinase pathway in bladder cancer. Cancer Res. 2009; 69(11): 4613-4620.

11. Babina IS, Turner NC. Advances and challenges in targeting FGFR signalling in cancer. Nature reviews Cancer. 2017; 17(5): 318-332.

12. Helsten T, Elkin S, Arthur E, et al. The FGFR Landscape in Cancer: Analysis of 4,853 Tumors by Next-Generation Sequencing. Clinical cancer research : an official journal of the American Association for Cancer Research. 2016; 22(1): 259-267.

13. Mohammadi M, Dikic I, Sorokin A, et al. Identification of six novel autophosphorylation sites on fibroblast growth factor receptor 1 and elucidation of their importance in receptor activation and signal transduction. Molecular and cellular biology. 1996; 16(3): 977-989.

14. Tiong $\mathrm{KH}$, Mah LY, Leong CO. Functional roles of fibroblast growth factor receptors (FGFRs) signaling in human cancers. Apoptosis: an international journal on programmed cell death. 2013; 18(12): 1447-1468.

15. Katoh M. FGFR inhibitors: Effects on cancer cells, tumor microenvironment and whole-body homeostasis (Review). International journal of molecular medicine. 2016; 38(1): 3-15.

16. Touat M, Ileana E, Postel-Vinay S, et al. Targeting FGFR Signaling in Cancer. Clinical cancer research: an official journal of the American Association for Cancer Research. 2015; 21(12): 2684-2694.

17. Jafari M, Ghadami E, Dadkhah T, et al. PI3k/AKT signaling pathway: Erythropoiesis and beyond. Journal of Cellular Physiology. 2019; 234(3): 2373-2385

18. Janku F, Yap TA, Meric-Bernstam F. Targeting the PI3K pathway in cancer: are we making headway?. Nature Reviews Clinical Oncology. 2018; 15(5): 273.

19. Guasch G, Ollendorff V, Borg JP, et al. $8 \mathrm{p} 12$ stem cell myeloproliferative disorder: the FOP-fibroblast growth factor receptor 1 fusion protein of the $\mathrm{t}(6 ; 8)$ translocation induces cell survival mediated by mitogen-activated protein kinase and phosphatidylinositol 3-kinase/Akt/mTOR pathways. Molecular \& Cellular Biology. 2001; 21(23): 8129-8142.

20. Gomez-Roman JJ, Saenz P, Molina M, et al. Fibroblast growth factor receptor 3 is overexpressed in urinary tract carcinomas and modulates the neoplastic cell growth. Clinical cancer research: an official journal of the American Association for Cancer Research. 2005; 11(2): 459-465.

21. Dubrulle J, Pourquie O. fgf8 mRNA decay establishes a gradient that couples axial elongation to patterning in the vertebrate embryo. Nature. 2004; 427(6973): 419-422

22. Kawase R, Ishiwata T, Matsuda Y, et al. Expression of fibroblast growth factor receptor 2 IIIc in human uterine cervical intraepithelial neoplasia and cervical cancer. International journal of oncology. 2010;36(2): 331-340.

23. Kurban G, Ishiwata T, Kudo M, et al. Expression of keratinocyte growth factor receptor (KGFR/FGFR2 IIIb) in human uterine cervical cancer. Oncology reports. 2004; 11(5): 987-991.

24. Chae YK, Ranganath K, Hammerman PS, et al. Inhibition of the fibroblast growth factor receptor (FGFR) pathway: the current landscape and barriers to clinical application. Oncotarget. 2017; 8(9): 16052-16074.
25. Gozgit JM, Squillace RM, Wongchenko MJ, et al. Combined targeting of FGFR2 and mTOR by ponatinib and ridaforolimus results in synergistic antitumor activity in FGFR2 mutant endometrial cancer models. Cancer chemotherapy and pharmacology. 2013; 71(5): 1315-1323.

26. Choi $\mathrm{CH}$, Chung JY, Kim JH, et al. Expression of fibroblast growth factor receptor family members is associated with prognosis in early stage cervical cancer patients. Journal of translational medicine. 2016; 14(1): 124.

27. Cohen PA, Jhingran A, Oaknin A, et al. Cervical cancer. Lancet. 2019; 393(10167): 169-182.

28. Siegel RL, Miller KD, Jemal A. Cancer statistics, 2019. CA: A Cancer Journal for Clinicians. 2019; 69(1):7-34

29. zur Hausen H. Papillomaviruses and cancer: from basic studies to clinical application. Nature reviews Cancer. 2002; 2(5): 342-350.

30. Ranieri D, Belleudi F, Magenta A, et al. HPV16 E5 expression induces switching from FGFR2b to FGFR2c and epithelial-mesenchymal transition. International journal of cancer. 2015; 137(1): 61-72.

31. Tamura R, Yoshihara K, Saito T, et al. Novel therapeutic strategy for cervical cancer harboring FGFR3-TACC3 fusions. Oncogenesis. 2018; 7(1): 4.

32. Spaans VM, Trietsch MD, Crobach $S$, et al. Designing a high-throughput somatic mutation profiling panel specifically for gynaecological cancers. PloS one. 2014; 9(3): e93451.

33. Weberpals JI, Lo B, Duciaume MM, et al. Vulvar Squamous Cell Carcinoma (VSCC) as Two Diseases: HPV Status Identifies Distinct Mutational Profiles Including Oncogenic Fibroblast Growth Factor Receptor 3. Clinical cancer research: an official journal of the American Association for Cancer Research. 2017; 23(15): 4501-4510

34. Torre LA, Trabert B, Desantis CE, et al. Ovarian cancer statistics, 2018. Histopathology. 2018; 68(4): 284-296.

35. Dieci MV, Arnedos M, Andre F, et al. Fibroblast growth factor receptor inhibitors as a cancer treatment: from a biologic rationale to medical perspectives. Cancer discovery. 2013; 3(3): 264-279.

36. Steele IA, Edmondson RJ, Bulmer JN, et al. Induction of FGF receptor 2-IIIb expression and response to its ligands in epithelial ovarian cancer. Oncogene. 2001; 20(41): 5878-5887.

37. Taniguchi $\mathrm{F}$, Itamochi $\mathrm{H}$, Harada $\mathrm{T}$, et al. Fibroblast growth factor receptor 2 expression may be involved in transformation of ovarian endometrioma to clear cell carcinoma of the ovary. International journal of gynecological cancer official journal of the International Gynecological Cancer Society. 2013; 23(5): 791-796

38. Byron SA, Gartside MG, Wellens CL, et al. FGFR2 mutations are rare across histologic subtypes of ovarian cancer. Gynecologic oncology. 2010; 117(1): 125-129.

39. Zaid TM, Yeung TL, Thompson MS, et al. Identification of FGFR4 as a potential therapeutic target for advanced-stage, high-grade serous ovarian cancer. Clinical cancer research : an official journal of the American Association for Cancer Research. 2013; 19(4): 809-820.

40. $\mathrm{Hu} \mathrm{L}$, Cong L. Fibroblast growth factor 19 is correlated with an unfavorable prognosis and promotes progression by activating fibroblast growth factor receptor 4 in advanced-stage serous ovarian cancer. Oncology reports. 2015; 34(5): 2683-2691.

41. Marme F, Hielscher T, Hug S, et al. Fibroblast growth factor receptor 4 gene (FGFR4) 388Arg allele predicts prolonged survival and platinum sensitivity in advanced ovarian cancer. International journal of cancer. 2012; 131(4): 586-591.

42. Siegel RL, KD M, A J. Cancer statistics, 2018. Ca A Cancer Journal for Clinicians. 2018; 68(1): 7-30.

43. Lee PS, Secord AA. Targeting molecular pathways in endometrial cancer: a focus on the FGFR pathway. Cancer treatment reviews. 2014; 40(4): 507-512.

44. Dutt A, Salvesen HB, Chen TH, et al. Drug-sensitive FGFR2 mutations in endometrial carcinoma. Proc Natl Acad Sci US A. 2008; 105(25): 8713-8717.

45. Pollock PM, Gartside MG, Dejeza LC, et al. Frequent activating FGFR2 mutations in endometrial carcinomas parallel germline mutations associated with craniosynostosis and skeletal dysplasia syndromes. Oncogene. 2007; 26(50): 7158-7162.

46. Korc M, Friesel RE. The role of fibroblast growth factors in tumor growth. Current cancer drug targets. 2009; 9(5): 639-651.

47. Konecny GE, Kolarova T, O'Brien NA, et al. Activity of the fibroblast growth factor receptor inhibitors dovitinib (TKI258) and NVP-BGJ398 in human endometrial cancer cells. Molecular cancer therapeutics. 2013; 12(5): 632-642.

48. Brooks AN, Kilgour E, Smith PD. Molecular pathways: fibroblast growth factor signaling: a new therapeutic opportunity in cancer. Clinical cancer research : an official journal of the American Association for Cancer Research. 2012; 18(7): 1855-1862.

49. Citores L, Bai L, Sorensen V, et al. Fibroblast growth factor receptor-induced phosphorylation of STAT1 at the Golgi apparatus without translocation to the nucleus. J Cell Physiol. 2007; 212(1): 148-156.

50. Harada D, Yamanaka Y, Ueda K, et al. Sustained phosphorylation of mutated FGFR3 is a crucial feature of genetic dwarfism and induces apoptosis in the ATDC5 chondrogenic cell line via PLCgamma-activated STAT1. Bone. 2007; 41(2): 273-281.

51. Lievens PM, Mutinelli C, Baynes D, et al. The kinase activity of fibroblast growth factor receptor 3 with activation loop mutations affects receptor trafficking and signaling. The Journal of biological chemistry. 2004; 279(41): 43254-43260. 
52. Ahmed Z, Schuller AC, Suhling K, et al. Extracellular point mutations in FGFR2 elicit unexpected changes in intracellular signalling. The Biochemical journal. 2008; 413(1): 37-49.

53. Hatch NE, Hudson M, Seto ML, et al. Intracellular retention, degradation, and signaling of glycosylation-deficient FGFR2 and craniosynostosis syndrome-associated FGFR2C278F. The Journal of biological chemistry. 2006; 281(37): 27292-27305.

54. Kang S, Li SZ, Wang N, et al. Association between genetic polymorphisms in fibroblast growth factor (FGF)1 and FGF2 and risk of endometriosis and adenomyosis in Chinese women. Human reproduction (Oxford, England). 2010; 25(7): 1806-1811.

55. Meng QH, Xu E, Hildebrandt MA, et al. Genetic variants in the fibroblast growth factor pathway as potential markers of ovarian cancer risk, therapeutic response, and clinical outcome. Clinical chemistry. 2014; 60(1): 222-232.

56. Li YP, Zhang L, Zou YL, et al. Association between FGFR4 gene polymorphism and high-risk HPV infection cervical cancer. Asian Pacific journal of tropical medicine. 2017; 10(7): 680-684.

57. Chen TH, Yang SF, Liu YF, et al. Association of Fibroblast Growth Factor Receptor 4 Genetic Polymorphisms With the Development of Uterine Cervical Cancer and Patient Prognosis. Reproductive sciences (Thousand Oaks, Calif). 2018; 25(1): 86-93.

58. Kandoth C, Schultz N, Cherniack AD, et al. Integrated genomic characterization of endometrial carcinoma. Nature. 2013; 497(7447): 67-73.

59. Jeske YW, Ali S, Byron SA, et al. FGFR2 mutations are associated with poor outcomes in endometrioid endometrial cancer: An NRG Oncology/Gynecologic Oncology Group study. Gynecologic oncology. 2017; 145(2): 366-373.

60. Gorringe KL, Jacobs S, Thompson ER, et al. High-resolution single nucleotide polymorphism array analysis of epithelial ovarian cancer reveals numerous microdeletions and amplifications. Clinical cancer research : an official journal of the American Association for Cancer Research. 2007; 13(16): 4731-4739.

61. Cappellen D, De Oliveira C, Ricol D, et al. Frequent activating mutations of FGFR3 in human bladder and cervix carcinomas. Nat Genet. 1999; 23(1): 18-20.

62. Rosty C, Aubriot MH, Cappellen D, et al. Clinical and biological characteristics of cervical neoplasias with FGFR3 mutation. Molecular cancer. 2005; 4(1): 15.

63. Bernard-Pierrot I, Brams A, Dunois-Larde C, et al. Oncogenic properties of the mutated forms of fibroblast growth factor receptor $3 \mathrm{~b}$. Carcinogenesis. 2006; 27(4): 740-747.

64. Xiang L, Li J, Jiang W, et al. Comprehensive analysis of targetable oncogenic mutations in chinese cervical cancers. Oncotarget. 2015; 6(7): 4968-4975.

65. Hao RH, Guo Y, Dong SS, et al. Associations of Plasma FGF2 Levels and Polymorphisms in the FGF2 Gene with Obesity Phenotypes in Han Chinese Population. Sci Rep. 2016; 6: 19868.

66. Zhu DL, Guo Y, Zhang Y, et al. A functional SNP regulated by miR-196a-3p in the 3'UTR of FGF2 is associated with bone mineral density in the Chinese population. Hum Mutat. 2017; 38(6): 725-735.

67. Liang G, Liu Z, Wu J, et al. Anticancer molecules targeting fibroblast growth factor receptors. Trends in pharmacological sciences. 2012; 33(10): 531-541.

68. Prieto-Dominguez N, Shull AY, Teng Y. Making way for suppressing the FGF19/FGFR4 axis in cancer. Future medicinal chemistry. 2018; 10(20): 2457-2470.

69. Gozgit JM, Wong MJ, Moran L, et al. Ponatinib (AP24534), a multitargeted pan-FGFR inhibitor with activity in multiple FGFR-amplified or mutated cancer models. Molecular cancer therapeutics. 2012; 11(3): 690-699.

70. Jonker DJ, Rosen LS, Sawyer MB, et al. A phase I study to determine the safety, pharmacokinetics and pharmacodynamics of a dual VEGFR and FGFR inhibitor, brivanib, in patients with advanced or metastatic solid tumors. Annals of oncology: official journal of the European Society for Medical Oncology. 2011; 22(6): 1413-1419.

71. Vergote I, Teneriello M, Powell MA, et al. A phase II trial of lenvatinib in patients with advanced or recurrent endometrial cancer: Angiopoietin-2 as a predictive marker for clinical outcomes. Journal of Clinical Oncology. 2013; 31(15): 5520-5520.

72. Makker V, Rasco DW, Dutcus CE, et al. A phase Ib/II trial of lenvatinib (LEN) plus pembrolizumab (Pembro) in patients (Pts) with endometrial carcinoma. American Society of Clinical Oncology; 2017; 35(15): 5598-5598.

73. Klempner SJ, Myers AP, Mills GB, et al. Clinical investigation of receptor and non-receptor tyrosine kinase inhibitors for the treatment of epithelial ovarian cancer. Expert opinion on pharmacotherapy. 2013; 14(16): 2171-2182.

74. Taurin S, Yang CH, Reyes M, et al. Endometrial Cancers Harboring Mutated Fibroblast Growth Factor Receptor 2 Protein Are Successfully Treated With a New Small Tyrosine Kinase Inhibitor in an Orthotopic Mouse Model. International journal of gynecological cancer : official journal of the International Gynecological Cancer Society. 2018; 28(1): 152-160.

75. Porta R, Borea R, Coelho A, et al. FGFR a promising druggable target in cancer: Molecular biology and new drugs. Critical reviews in oncology/ hematology. 2017; 113: 256-267.

76. Gavine PR, Mooney L, Kilgour E, et al. AZD4547: an orally bioavailable, potent, and selective inhibitor of the fibroblast growth factor receptor tyrosine kinase family. Cancer Res. 2012; 72(8): 2045-2056.

77. Kwak Y, Cho H, Hur W, et al. Antitumor Effects and Mechanisms of AZD4547 on FGFR2-Deregulated Endometrial Cancer Cells. Molecular cancer therapeutics. 2015; 14(10): 2292-2302.
78. Packer LM, Geng X, Bonazzi VF, et al. PI3K Inhibitors Synergize with FGFR Inhibitors to Enhance Antitumor Responses in FGFR2(mutant) Endometrial Cancers. Molecular cancer therapeutics. 2017; 16(4): 637-648.

79. Patani H, Bunney TD, Thiyagarajan N, et al. Landscape of activating cancer mutations in FGFR kinases and their differential responses to inhibitors in clinical use. Oncotarget. 2016; 7(17): 24252-24268.

80. Perera TPS, Jovcheva E, Mevellec L, et al. Discovery and Pharmacological Characterization of JNJ-42756493 (Erdafitinib), a Functionally Selective Small-Molecule FGFR Family Inhibitor. Molecular cancer therapeutics. 2017; 16(6): 1010-1020.

81. Presta M, Chiodelli P, Giacomini A, et al. Fibroblast growth factors (FGFs) in cancer: FGF traps as a new therapeutic approach. Pharmacology \& therapeutics. 2017; 179: 171-187.

82. Harding TC, Long L, Palencia S, et al. Blockade of nonhormonal fibroblast growth factors by FP-1039 inhibits growth of multiple types of cancer. Science translational medicine. 2013; 5:178-139.

83. Dienstmann R, Rodon J, Prat A, et al. Genomic aberrations in the FGFR pathway: opportunities for targeted therapies in solid tumors. Annals of oncology : official journal of the European Society for Medical Oncology. 2014; 25(3): 552-563.

84. Hallinan N, Finn S, Cuffe $\mathrm{S}$, et al. Targeting the fibroblast growth factor receptor family in cancer. Cancer treatment reviews. 2016; 46: 51-62.

85. Theillet C, Adelaide J, Louason G, et al. FGFRI and PLAT genes and DNA amplification at $8 \mathrm{p} 12$ in breast and ovarian cancers. Genes, chromosomes \& cancer. 1993; 7(4): 219-226.

86. Hierro C, Rodon J, Tabernero J. Fibroblast Growth Factor (FGF) Receptor/FGF Inhibitors: Novel Targets and Strategies for Optimization of Response of Solid Tumors. Seminars in oncology. 2015; 42(6): 801-819.

87. Li Y, Mangasarian K, Mansukhani A, et al. Activation of FGF receptors by mutations in the transmembrane domain. Oncogene. 1997; 14(12): 1397-1406.

88. Wilkie $\mathrm{AO}$, Slaney $\mathrm{SF}$, Oldridge $\mathrm{M}$, et al. Apert syndrome results from localized mutations of FGFR2 and is allelic with Crouzon syndrome. Nat Genet. 1995; 9(2): 165-172.

89. Steinberger D, Vriend G, Mulliken JB, et al. The mutations in FGFR2associated craniosynostoses are clustered in five structural elements of immunoglobulin-like domain III of the receptor. Hum Genet. 1998; 102(2): 145-150.

90. Johnson D, Wall SA, Mann S, et al A novel mutation, Ala315Ser, in FGFR2: a gene-environment interaction leading to craniosynostosis? European journal of human genetics: EJHG. 2000; 8(8): 571-577.

91. Przylepa KA, Paznekas W, Zhang M, et al. Fibroblast growth factor receptor 2 mutations in Beare-Stevenson cutis gyrata syndrome. Nat Genet. 1996; 13(4): 492-494.

92. Kan SH, Elanko N, Johnson D, et al. Genomic screening of fibroblast growth-factor receptor 2 reveals a wide spectrum of mutations in patients with syndromic craniosynostosis. American journal of human genetics. 2002; 70(2): $472-486$

93. Tavormina PL, Bellus GA, Webster MK, et al. A novel skeletal dysplasia with developmental delay and acanthosis nigricans is caused by a Lys650Met mutation in the fibroblast growth factor receptor 3 gene. American journal of human genetics. 1999; 64(3): 722-731. 